84

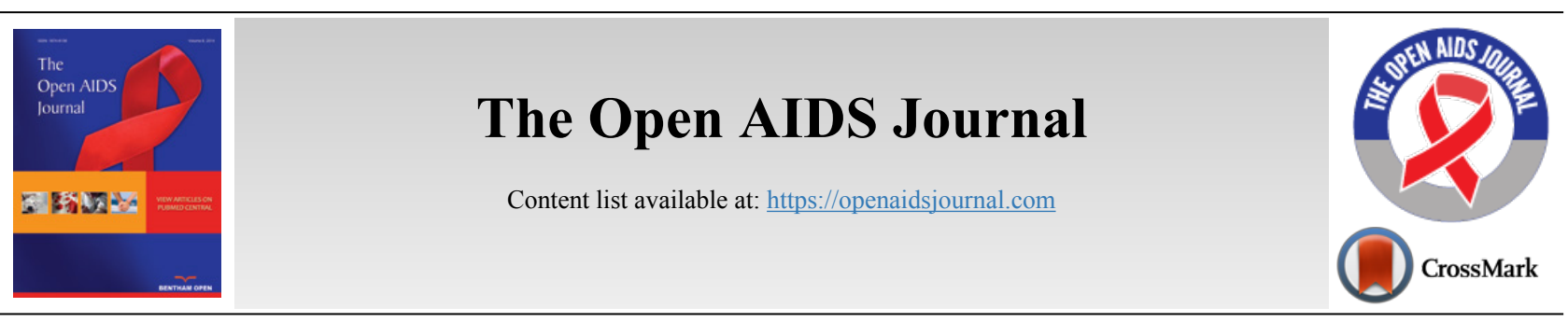

RESEARCH ARTICLE

\title{
Knowledge, Attitude and Practices Regarding HIV and AIDS among High School Learners in South Africa
}

\author{
Thanduxolo Fana, ${ }^{1, *}$ \\ ${ }^{\prime}$ Department of Public Management and Leadership, Nelson Mandela University, Port Elizabeth, South Africa
}

\author{
Abstract: \\ Background: \\ Globally, millions are infected with HIV/AIDS, and more than half of them are adolescents aged between 12-25 years. Inadequate knowledge, \\ negative attitudes, and risky practices are major barriers to HIV/AIDS prevention. This study seeks to establish the knowledge, attitudes, and \\ practices regarding HIV/AIDS among high school learners in South Africa. \\ Methods:
}

Data were collected from a randomly selected sample of 422 learners from two high schools using pre-tested questionnaires. Data were analysed using SPSS version 16.

Results:

Participants had good HIV/AIDS knowledge, attitudes, and practice levels, however, misconceptions about transmission, negative attitudes, and risky behaviour or practices were also found. Knowledge was associated with age, social status, and sources of information. Attitudes were associated with gender, age, race, social status and sources of information. Practices were associated with age, race, social class, and sources of information $(\mathrm{p}=<0.05)$.

\section{Conclusion:}

Sex education (life orientation) in school and HIV/AIDS awareness programs in communities need to be intensified in order to rectify misconceptions, negative and discriminatory attitudes, unsafe and risky practices, as schools and healthcare workers were found to be the main source of HIV/AIDS information.

Keywords: Attitudes, High school, HIV and AIDS, Knowledge, Learners, Practice.

Article History Received: June 24, 2021 Revised: September 15, 2021

Accepted: October 12, 2021

\section{BACKGROUND AND INTRODUCTION}

Human Immunodeficiency Virus (HIV) and Acquired Immune Deficiency Syndrome (AIDS) were identified in 1981 among homosexuals in the United States of America (USA). Since then, it has spread rapidly to other countries around the world, and it has become a global health challenge and a threat to human rights and development. HIV and AIDS have become a pandemic globally [1 - 3]. Globally, more than 74.9 million people have been infected with HIV since the start of the pandemic. 32 million people are reported to have died from AIDS-related illness worldwide. In 2018, the Joint United

* Address correspondence to this author at Department of Public Management and Leadership, Nelson Mandela University, Port Elizabeth, South Africa; Tel: 0732301771; E-mail: unamthanduxolo@gmail.com
Nations Program on HIV and AIDS (UNAIDS) reported that 37.9 million people were living with HIV and AIDS globally, and of these, 36.2 million were adults and 1.7 million were children $(<15$ years old). 1.6 million new infections were among people with ages 15 and older, and 160,000 infections were among children with ages 0-14. Globally, deaths from AIDS-related illnesses were estimated at 770,000 [4].

Globally, Sub-Saharan Africa is the most affected region, with almost two-thirds of the HIV-infected people globally living here. The majority (71\%) of People Living with HIV and AIDS (PLWHA), newly infected (70\%), as well as AIDSrelated deaths (74\%), are found in Sub-Saharan Africa. South Africa (SA) is one of the countries in Sub-Saharan Africa and has the biggest HIV epidemic in the world, with 7.7 million people living with HIV. There were 240,000 new HIV 
infections and 71,000 AIDS-related death in SA. The HIV prevalence among the adult population in SA is 20.4 percent. It also differs from province to province [4].

It is also stated that HIV prevalence among females between the ages of $15-49$ was 26.3 percent compared to 14.8 percent in males within the same age group. The three provinces with the highest HIV prevalence rate among 15-49 years old were KwaZulu-Natal (KZN), 27\%, followed by Free State (FS), 25.5\%, and Eastern Cape (EC), 25.2\% [5].

The HIV virus has no boundaries, as rates of infection continue to rise in both adults and children. It is also of interest to note that in Africa, almost $90 \%$ of HIV transmission in Africa is through sexual intercourse [6]. Young people, particularly adolescents, are at great risk of contracting the virus through sexual activity as well as sexual exploitation and abuse. Globally, 10.3 million youth aged $15-24$ years are HIV positive. Research has also shown that adolescents aged 15-24 years constitute the largest population of HIV-infected subjects [7]. It is also of interest to note that females are said to be the most affected compared to males in the 15-24 age group [4]. Research has shown that youth are becoming sexually active at an earlier age. Some studies have reported the age at first intercourse to be below 11 years [8] and of high school age [9]. Studies have also found that youth have pre-marital sex [10]. At these ages (15-24 years), youth are more likely to engage in risky behaviours and unsafe sex practices [1] due to the lack of adequate and correct information [11], poor access to condoms [12], and reproductive healthcare service, substance abuse [13] and engaging in sexual exchanges to meet needs [14].

The high HIV prevalence, especially among youth in the Eastern Cape, compels us to assess HIV and AIDS knowledge, attitudes, and practices among high school learners in the area; Improving our understanding of the HIV pandemic is a crucial step towards the fight against HIV and AIDS. Adequate information about HIV and AIDS can assist in the promotion of positive attitudes, reduction of stigmatisation, as well as behaviour modification from incorrect and unsafe practices to correct and safe practices [15], thereby curbing its spread [1]. This has been the focus of several HIV and AIDS prevention interventions that were conducted in both rural and urban areas of South Africa [16].

Conflicting findings were revealed in several studies that were conducted to assess HIV and AIDS knowledge, attitudes and practices among learners. HIV and AIDS knowledge was below average; there were misconceptions, risky practices were discovered, and there were negative attitudes toward HIV and AIDS patients $[9,15,17,18$.$] . Other studies revealed good$ HIV and AIDS knowledge, safe sexual practices and positive attitudes towards people living with HIV and AIDS [19, 20]. HIV risk is associated with distorted knowledge or perceptions of reality in HIV and AIDS prevention.

The major factor for HIV transmission is engaging in highrisk sexual behaviours. It appears as if some people do not fear HIV infection [1, 21 - 23]. Other researchers are of the view that some people will still have sex without condoms due to a strong negative attitude towards condoms even after knowing that the chances of being infected with HIV will be high [23].
Lack of prevention and treatment information, limited access to healthcare services, and societal norms predispose community especially young women and girls, to violence; early marriages are some of the factors that predispose them to high-risk sexual practices [24].

Although antiretroviral drugs have resulted in a decline in the death rate and progression of HIV to AIDS, the rate of a new infection is still a cause for concern in SA. HIV and AIDS have no cure, therefore, prevention is the best available option that we have for combating and curbing its spread $[1,2]$. The above situation also highlights the significance of raising awareness of the risk that is associated with sexual behaviour and HIV and AIDS. Research has shown that good HIV and AIDS-related knowledge does not always translate into good behaviour or safe practices [21]. There is a problematic relationship between knowledge of disease and behaviour, especially when considering the fact that youth can show high knowledge levels of diseases, but some still engage in risky behaviours $[16,25]$.

There is a need to avail adequate and factual information about HIV and AIDS in order to enable people to make informed and responsible choices regarding their sexual behaviour and practices. There is a gap in research regarding the relationship between knowledge, behaviour and practices. There is also a lack of research studies that shows the link between knowledge of HIV and community members engaging in health-preventative behaviours in South Africa [26]. There is a paucity of studies addressing HIV and AIDS knowledge, attitudes and practices among high school learners, especially in Nelson Mandela Municipality Eastern Cape Province of South Africa, and this study seeks to fill that gap.

High school learners (adolescents and young adults) may be at higher risk of engaging in risky sexual behaviour, especially if they are under the influence of alcohol or drugs, respond to peer pressure, or lack maturity [27]. High school learners fall in this age group.

Regardless of being acquainted with some form of knowledge and education, high school learners still engage in risky behaviour or unsafe practices. Thus, changing risky behaviour and mindsets will probably lead to safer decisionmaking among high school learners as they progress in their lives and either go to tertiary institutions or join the workforce.

\section{MATERIALS}

\subsection{Study Settings, Study Site and Study Design}

This study was conducted among high school learners in the Nelson Mandela Municipality in the Eastern Cape Province of South Africa. The Eastern Cape is one of the nine provinces that were formed after the first democratic election, which was held on 27 April 1994 in South Africa. Eastern Cape is the second largest province in South Africa and covers almost $13.8 \%$ of the country's land, and it has the third-largest population with $6,498,700$ people, accounting for $12 \%$ of the country's population. The Eastern Cape is one of the most rural and poorest provinces in South Africa. Subsistence agriculture predominates in the former homelands, resulting in widespread poverty. The Nelson Mandela Municipality is one of the 
metropolitan districts in the Eastern Cape Province of South Africa that has a population of just over one million. The Nelson Mandela Municipality has an unemployment rate of $36 \%$ that is below both provincial and national averages (45. $3 \%$ and $36.8 \%$, respectively) $[1,16]$.

The study was conducted in the Nelson Mandela Municipality in order to establish HIV and AIDS knowledge, attitudes and practices of HIV and AIDS among high school learners. The two high schools that participated in this study were selected from Uitenhage and the Port Elizabeth education district.

This study is cross-sectional and descriptive in nature. At one level, the researcher used random sampling to select a school from each of the two districts. This was done by writing down the names of the schools in each of the two districts and allocating numbers to each school, putting the names and numbers in two boxes as per district, and then picking up one number from each box. At another level, participants were selected through purposive sampling as only grade $10-12$ learners were recruited to participate. Participants were picked at random from school registers for grades 10 to 12; every fourth learner was chosen until all 422 students had been chosen (211 per school) . Participants were requested to sign consent forms, and parental consent and assent were also sought for those who were below 18 years.

\subsection{Inclusion and Exclusion Criteria}

The study included those who gave consent and were 15 years and above in grade $10-12$. School learners who refused to give consent, and were below grade 10 and less than 15 years of age were excluded from this study.

\subsection{The Pilot Study, Data Collection Instruments and Data Collection Technique}

A structured closed-ended pre-tested questionnaire was used to collect data. The questionnaire was written in English and had four sections. The first part of the questionnaire dealt with the demographic characteristics of the participants. The second part of the questionnaire was related to HIV and AIDS knowledge. The third part was related to attitudes and perceptions. The fourth and last section of the questionnaire was related to prevention practices. The reliability of the questionnaire was established through a pilot study, which preceded this study. Thirty people participated in the pilot study, and its results were not included in the findings of the main study. The validity was established through qualitative inter-rater assessment of its usefulness in getting the required information from participants. Corrections were made to the time from 45 to 30 minutes. The questionnaire consisted of items that required the participants to tick a response that best represented their knowledge, attitude and practices of HIV and AIDS. The rating was as follows: 'agree' was worth 1 point and 'disagree' 2 points. For each individual item, responses that were coded as correct yielded 1 point, incorrect answers and missing data got no points. Each participant was given a score ranging from 0 to 15 for knowledge, 0 to 5 for attitudes, and 0 to 10 for practices. Knowledge, attitudes and practices scores were classified as high from $70 \%$ and above. Higher scores indicated higher levels of knowledge, attitudes, and practices about HIV and AIDS.

\subsection{Data Analysis}

Data were checked for completion; it were sorted and entered into Microsoft Excel 2013 spreadsheet. Data were exported from the spreadsheet to Statistical Package for Social Sciences (SSPS), version 16. The results were presented using descriptive summary measures, such as frequency, percentages. Pearson's chi-square test was done to establish relationships between the socio-demographic and HIV and AIDS knowledge, attitudes and practices.

\subsection{Ethical Considerations}

Ethical clearance for this study was obtained from the University Research Ethics Committee (259/18) before conducting this study. Once the application for ethical clearance was approved, parental assent was sought for participants younger than 18 years and consent forms were given to the selected participants (18 years and above). The participants were made aware of their right to participate or not to participate in the study. The researcher told the participants that their participation was on a voluntary basis and that they were not going to be paid for participating in the study or penalised for withdrawing their participation. Participants were informed that the information they provided in the study would be treated as confidential and that participants would be regarded as anonymous.

\section{RESULTS}

\subsection{Socio-Demographic Variables of the Respondents}

The results in Table $\mathbf{1}$ reveal that the majority of the respondents were females $(52 \%)$, Black $(68 \%)$, and aged between $18-21$ years $(52 \%)$. The results also reveal that the majority of the learners were living in informal settlements $(68 \%)$, and most of them were from families of low social class $(69 \%)$.

Table 1. Socio-demographic variables of the respondents $(\mathrm{N}$ = 422).

\begin{tabular}{|c|c|c|}
\hline Variables & Freq. & \% \\
\hline Gender & & \\
Males & 202 & 48 \\
Females & 220 & 52 \\
\hline Race & & \\
Black & 287 & 68 \\
Coloured & 135 & 32 \\
\hline Age & 203 & 48 \\
15-17 & 219 & 52 \\
18- 21 & & \\
\hline Type of Settlements & & \\
Formal & 135 & 32 \\
Informal & 287 & 68 \\
\hline Social Status & & \\
Low & 291 & 69 \\
Middle & 110 & 26 \\
High & 21 & 5 \\
\hline
\end{tabular}




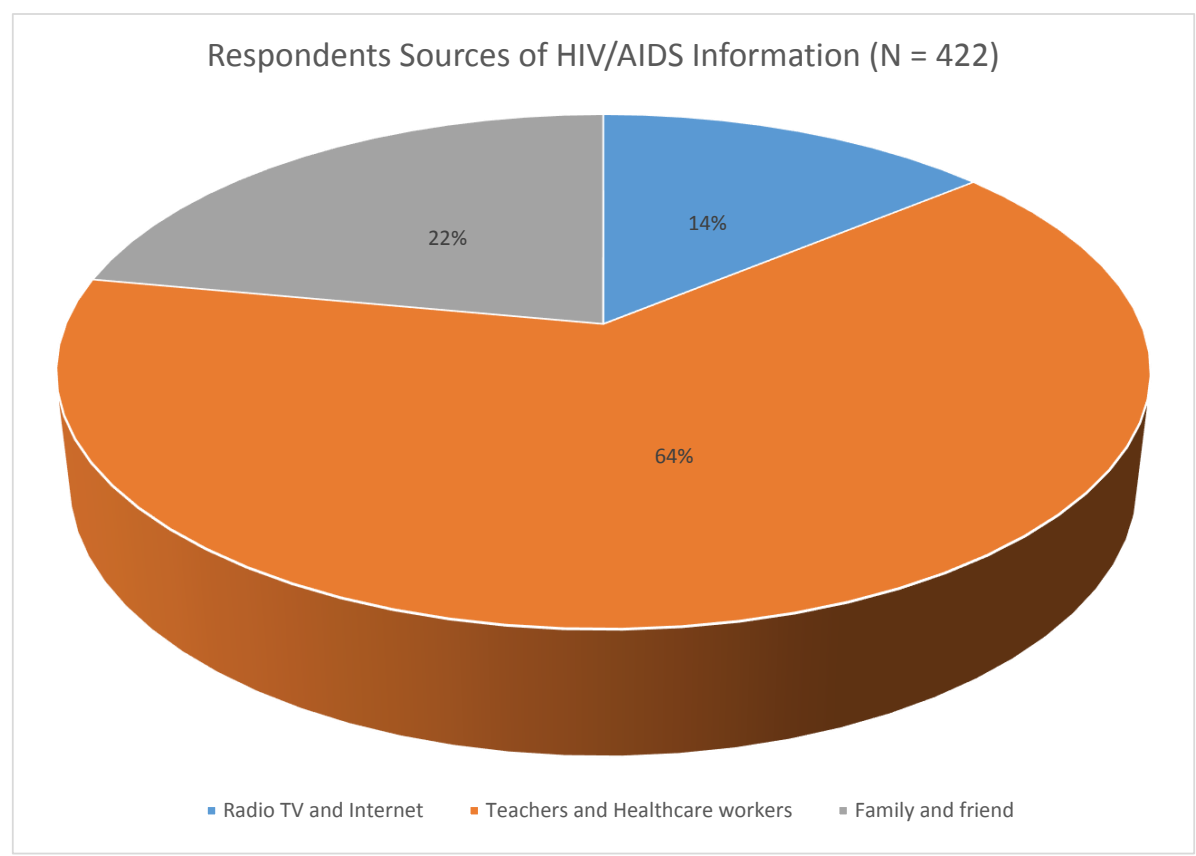

Fig. (1). Respondents sources of HIV and AIDS Information.

\subsection{Sources of HIV and AIDS Information}

The results in Fig. (1) shows that majority of respondents have indicated that they have heard about HIV and AIDS through teachers and healthcare workers (64\%).

\subsection{Knowledge Regarding the Route of Transmission, Prevention and Control of HIV/AIDS}

The results in Table 2 shows that the majority of the respondents $(100 \%)$ knew that HIV can spread through sexual intercourse, through blood transfusion (89\%), from a mother to a child (85\%) and by sharing needles and syringes (75\%). The majority of the respondents also knew that HIV and AIDS cannot be transmitted or spread through witchcraft (78\%), mosquito bites $(86 \%)$, sharing or sitting on the same toilet seat, or sharing a toilet with the person living with HIV and AIDS $(90 \%)$ and handshakes (100\%) with an infected person.

The results also indicate that the majority of the respondents $(91 \%)$ knew that there is no expensive vaccine to cure HIV and AIDS (96\%) and that antiretroviral drugs cannot cure HIV and AIDS (96\%); HIV and AIDS cannot be cured by having sexual intercourse with a virgin $(91 \%)$. Results also showed that the majority ( $81 \%$ ) of the respondents knew that HIV can also infect circumcised people. Lastly, the results illustrate that the majority of the research respondents knew that the spread of HIV and AIDS can be controlled by abstaining (95\%), and having one partner and being faithful $(92 \%)$.

\subsection{Attitudes of Respondents Regarding HIV and AIDS}

The results in Table 3 shows that the majority (70\%) of the respondents indicated that they were willing to take care of a relative living with HIV and AIDS and $72 \%$ indicated that they would continue being friends with someone diagnosed with HIV. The results also show that just over half $(52 \%)$ of the respondents indicated that they would continue buying groceries from someone they found out to be HIV positive. The results also show that the majority $(69 \%$ and $65 \%)$ of the respondents also believed that a HIV-positive student and a HIV-positive teacher should be allowed to continue studying and teaching at the school, respectively.

Table 2. Statements relating to transmission, prevention, and control of HIV/AIDS $(N=422)$.

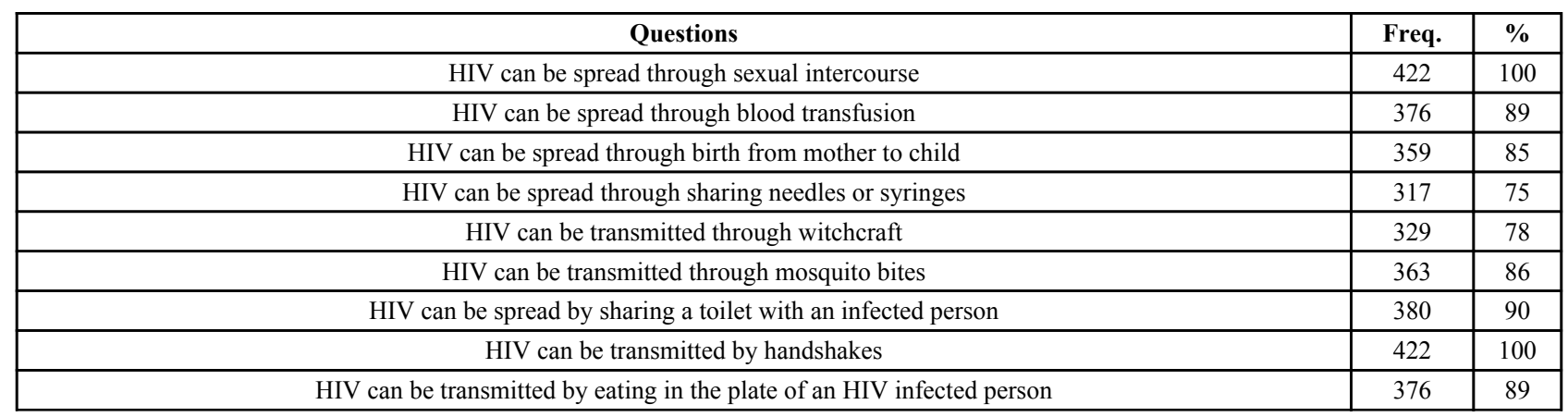


(Table 2) contd.....

\begin{tabular}{|c|c|c|}
\hline Questions & Freq. & $\%$ \\
\hline HIV infection can be cured by having sexual intercourse with a virgin & 380 & 91 \\
\hline HIV and AIDS can be cured using an expensive vaccine & 405 & 96 \\
\hline Antiretroviral (ARV) treatment can cure HIV and AIDS & 405 & 96 \\
\hline HIV spread can be controlled by abstaining & 404 & 95 \\
\hline HIV cannot infect circumcised people & 371 & 81 \\
\hline HIV spread can be controlled by remaining faithful to a single partner & 388 & 92 \\
\hline
\end{tabular}

Table 3. Attitudes of respondents regarding HIV/AIDS $(\mathrm{N}=422)$.

\begin{tabular}{|l|l|l|}
\hline \multicolumn{1}{|c|}{ Questions } & Freq. \\
\hline Will you be willing to take care of a relative with HIV and AIDS & 295 & 70 \\
\hline Will you continue being a friend of someone diagnosed with HIV & 304 & 72 \\
\hline Will you continue buying groceries from someone you found out is HIV+ & 219 & 52 \\
\hline Should an HIV+ student be allowed to continue studying at your school & 69 \\
\hline Should a HIV+ teacher be allowed to continue teaching at your school & 65 \\
\hline
\end{tabular}

\subsection{Practices of Respondents Regarding HIV and AIDS}

The results in Table 4 shows that the majority $(70 \%)$ of the respondents indicated that they had sexual intercourse, undergone a HIV test (67\%), knew their HIV status (67\%) and did not use injectable drugs $(80 \%)$. The results also show that of those who had sexual intercourse, $30 \%$ did not make use of condoms during their first sexual intercourse, $45 \%$ did not make use of condoms during their last sexual intercourse. Results further revealed that those who had sexual intercourse (5\%) also had oral sex with other men and (43\%) had sex with multiple partners in the previous year. The results also showed that $(40 \%)$ those who had sexual intercourse stopped having sex when a condom bursts, and $26 \%$ had reported having had sexual intercourse while under the influence of alcohol.

\subsection{Association between Socio-demographic Factors and HIV/AIDS KAP}

The results in Table $\mathbf{5}$ shows a significant association between knowledge and age, social status, and sources of information $(p=<0.05)$. The results also revealed that there was no significant association between knowledge and gender, race and type of settlement $(\mathrm{p}=>0.05)$.

Table 4. Practices of respondents with regard to HIV/AIDS $(\mathrm{N}=422)$.

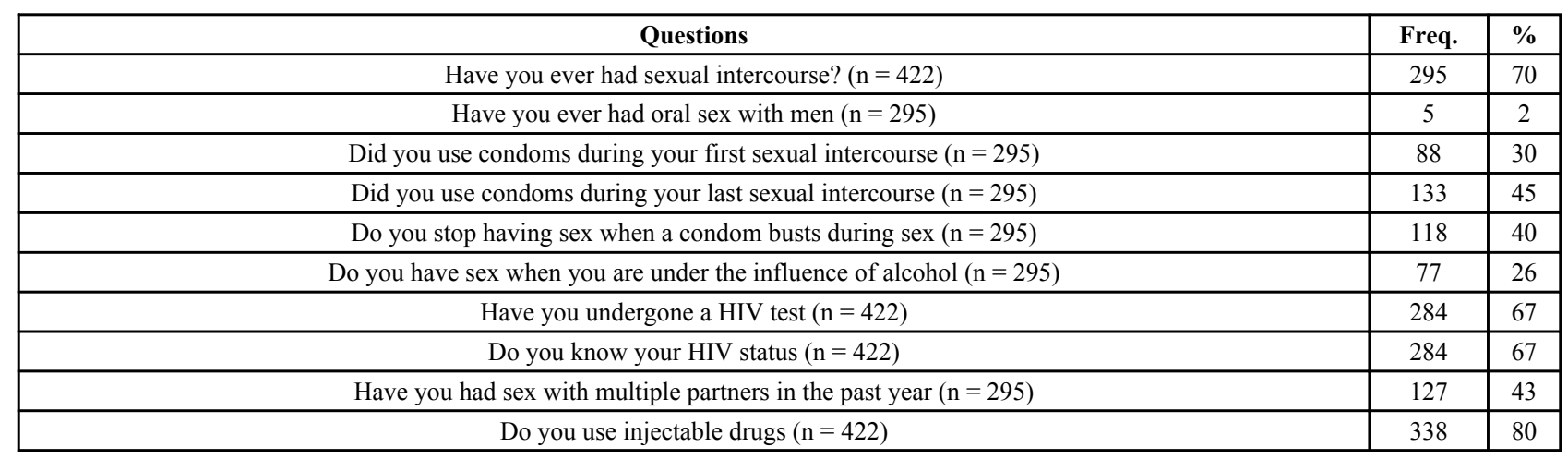

Table 5. Association between socio-demographic factors and HIV/AIDS KAP $(N=422)$.

\begin{tabular}{|c|c|c|c|c|c|c|c|c|c|}
\hline \multirow{2}{*}{$\begin{array}{c}\text { Variables } \\
\text { Gender }\end{array}$} & \multicolumn{2}{|c|}{ Knowledge Scores } & \multirow{2}{*}{$\frac{P-\text { Value }}{-}$} & \multicolumn{2}{|c|}{ Attitude Score } & \multirow{2}{*}{$\begin{array}{c}\text { P-Value } \\
-\end{array}$} & \multicolumn{2}{|c|}{ Practices Scores } & \multirow{2}{*}{$\begin{array}{c}\text { P-Value } \\
-\end{array}$} \\
\hline & - & - & & - & - & & - & - & \\
\hline Male & 93 & 109 & 0.436 & 139 & 63 & 0.001 & 117 & 85 & 0.664 \\
\hline Female & 93 & 127 & - & 183 & 37 & - & 132 & 88 & - \\
\hline Age & - & - & - & - & - & - & - & - & - \\
\hline $15-17$ & 112 & 91 & 0.001 & 138 & 65 & 0.001 & 136 & 67 & 0.001 \\
\hline $18-21$ & 74 & 145 & - & 184 & 35 & - & 112 & 107 & - \\
\hline Race & - & - & - & - & - & - & - & - & - \\
\hline Black & 123 & 164 & 0.462 & 210 & 77 & 0.006 & 141 & 146 & 0.001 \\
\hline Coloured & 63 & 72 & - & 115 & 20 & - & 108 & 27 & - \\
\hline
\end{tabular}


(Table 5) contd.....

\begin{tabular}{|c|c|c|c|c|c|c|c|c|c|}
\hline \multirow{2}{*}{$\begin{array}{c}\text { Variables } \\
\text { Social status }\end{array}$} & \multicolumn{2}{|c|}{ Knowledge Scores } & \multirow{2}{*}{$\begin{array}{c}\text { P-Value } \\
-\end{array}$} & \multicolumn{2}{|c|}{ Attitude Score } & \multirow{2}{*}{$\frac{\text { P-Value }}{-}$} & \multicolumn{2}{|c|}{ Practices Scores } & \multirow{2}{*}{$\frac{\text { P-Value }}{-}$} \\
\hline & - & - & & - & - & & - & - & \\
\hline Low & 61 & 230 & 0.001 & 256 & 35 & 0.001 & 160 & 131 & 0.020 \\
\hline Middle & 109 & 1 & - & 59 & 51 & - & 77 & 33 & - \\
\hline High & 16 & 5 & - & 8 & 13 & - & 11 & 10 & - \\
\hline Settlement & - & - & - & - & - & - & - & - & - \\
\hline Formal & 72 & 84 & 0.510 & 41 & 115 & 0.338 & 83 & 73 & 0.075 \\
\hline Informal & 114 & 152 & - & 59 & 207 & - & 165 & 101 & - \\
\hline Source of info & - & - & - & - & - & - & - & - & - \\
\hline Teachers \& CHW & 149 & 121 & 0.001 & 192 & 78 & 0.001 & 143 & 127 & 0.001 \\
\hline Radio, TV \& Internet & 34 & 25 & - & 44 & 15 & - & 57 & 2 & - \\
\hline Friends and family & 1 & 92 & - & 87 & 6 & - & 47 & 46 & - \\
\hline
\end{tabular}

The results also show that attitudes were significantly associated with gender, age, race, social status and sources information $(\mathrm{p}=<0.05)$. There were no significant associations between attitudes and type of settlement $(\mathrm{p}=>0.05)$. Lastly, the results further illustrate that practices were significantly associated with age, race, social class and sources of information $(\mathrm{p}=<0.05)$. There was no significant association between practices, gender and type of settlement $(\mathrm{p}=>0.05)$.

\section{DISCUSSION}

This study sought to establish knowledge, attitudes, and practices regarding HIV and AIDS among high school learners in the Eastern Cape Province of South Africa. We discovered that high school learners had high knowledge about HIV and AIDS transmission. All respondents knew that HIV and AIDS were spread through sexual intercourse and not through handshakes. Our study also found that some of the high school learners had misconceptions and distorted information about HIV and AIDS transmission modes and methods. The findings illustrate that the majority of the respondents knew that HIV and AIDS were spread through blood transfusion (89\%), from a mother to a child ( $85 \%)$, and by sharing needles and syringes (75\%). The study also found that the majority of the respondents also knew that HIV and AIDS cannot be transmitted or spread through witchcraft (78\%), mosquito bites $(86 \%)$, sharing or sitting on the same toilet seat, or sharing a toilet with the person living with HIV and AIDS (90\%). The findings of this study are similar to those of other studies carried out in other African countries, in which most respondents mentioned sexual intercourse, sharing of contaminated razor and needles, blood transfusion, and mother to child transmission as modes of HIV and AIDS transmission $[15,28,29]$.

Our findings are also in contrast to the results of a study that was conducted in Gabon, where half of the respondents indicated that HIV and AIDS were spread through eating and drinking from the same plate and cup or glass, wearing the same clothes, and sharing a toilet with a people living with HIV and AIDS. This study has also found that teachers and healthcare workers were the main sources of information regarding HIV and AIDS. Changes to high school curriculum (introduction of life orientation) and extensive health education and awareness campaigns that have been carried out both in urban and the remote and rural areas of South Africa might have resulted in the increase in HIV and AIDS knowledge of the participants. Life Orientation empowers learners with sound HIV and AIDS knowledge [30]. Our findings are similar to those of conducted studies [31 - 33], but in contrast to the findings of [34], where the majority of respondents indicated that church $(53 \%)$, parents $(35 \%)$ and school $(10 \%)$ were the main sources of HIV and AIDS information.

Although our study showed high knowledge regarding HIV and AIDS transmission modes and methods, misconceptions were observed among some of the respondents. A small portion of the respondents believed that HIV and AIDS could be transmitted through witchcraft (22\%), mosquito bites (14\%) and sharing a toilet with people living with HIV and AIDS (10\%). The results also showed that $5 \%$ and $8 \%$ of the respondents believed that abstinence and being faithful to one partner cannot be effective in controlling the spread of HIV and AIDS, respectively. The results further show that $4 \%$ of the respondents believed that there was an expensive vaccine to cure HIV and AIDS and that antiretroviral drugs cure HIV and AIDS; 9\% still believed that having sexual intercourse with a virgin could cure HIV and AIDS.

This is a cause for concern especially considering the fact that women cannot successfully negotiate safe sexual practices with their males due to their dominance and also due to the gender-based violence perpetrated by men towards women and girls $[1,16]$. The belief of the availability of a cure for HIV and AIDS might be attributed to the observed slow progression of HIV and AIDS and the reduced mortality rates among people living with HIV and AIDS, who are on antiretroviral treatment. The results also showed that $19 \%$ of the respondents believed that circumcised people cannot be infected with HIV and AIDS. This confusion might also be a result of information disseminated, which indicates reduced risks of HIV infection among people that have undergone circumcision. The findings highlight the need for intensified HIV and AIDS education.

Our findings are in line with those of a study that was conducted in Gabon, where almost half of the respondents believed that HIV and AIDS could be transmitted by eating from the same dish, drinking from the same cup and sharing clothes and toilet with a person living with HIV and AIDS [20]. Similar results were also found in a study that was conducted in Cameroon, where respondents did not know that HIV and AIDS could be transmitted by sex with an infected partner (15\%) and non-usage of condoms (14\%) [9]. It is of great concern that some of the respondents showed poor 
knowledge with regard to transmission, prevention and control of HIV and AIDS. There is an association between sexual behaviour and misconceptions in HIV knowledge [35]. Misconceptions and distorted information can lead to risky behaviours, such as unprotected sex, having multiple sexual partners, having sexual intercourse while under the influence of alcohol and sharing needles and syringes, and these can expose people to HIV infection [1, 16, 22].

These findings highlight the need to intensify health education and awareness campaigns, especially at schools, and target youth.

In this study, $67 \%$ of the participants had positive attitudes towards people living with HIV and AIDS, while a third of the participants had negative attitudes. Our findings are similar to those of a study [15], where 59\% of the respondents had positive attitudes towards people living with HIV and AIDS, and $41 \%$ had negative attitudes. Despite the above findings, our study found that the majority of the respondents indicated the willingness to take care of relatives living with HIV and AIDS (70\%) and $72 \%$ showed a willingness to continue the friendship with someone diagnosed with HIV and AIDS. Only half $(52 \%)$ of the respondents indicated a willingness to continue buying groceries from someone who was HIV positive. This study also found that the majority $(69 \%$ and $65 \%$ ) of the respondents also believed that an HIV-positive student and an HIV-positive teacher should be allowed to continue studying and teaching at the school, respectively. These findings indicate that some learners accepted people living with HIV and AIDS. Our findings are in contrast to the findings of a study [20], where less than half of the respondents showed positive attitudes on issues such as buying food from an HIV positive shopkeeper, and where learners were against being taught by HIV positive teacher and the fact that an HIVpositive student should be allowed to study [36]. Stigma and discriminatory attitudes towards people living with HIV and AIDS is a barrier to the efforts of curbing the spread of the disease $[1,9]$.

This study found that $70 \%$ of the respondents had a history of sexual intercourse, with $30 \%$ having had sex without condoms during the first sexual intercourse and $45 \%$ not using a condom during their last sexual intercourse.

Some of the findings of this study are: of those who had a history of sexual intercourse, $5 \%$ have had a sexual experience with men in the form of oral sex; of those who were sexually active, $43 \%$ had sex with multiple partners in the previous year; $26 \%$ of those who have had sexual experiences had sexual intercourse while under the influence of alcohol; $40 \%$ of those who had sexual history stopped having sexual intercourse when they found out that a condom had burst; $67 \%$ had done an HIV test and knew their HIV status, while $80 \%$ indicated that they were not using injectable drugs. The results of this study are similar to those of a study conducted [20,32], where it was found that $73 \%$ of the school children had a history of sexual intercourse, and $70 \%$ had made use of condoms. Our findings are also in contrast to studies [15,37], where it was found that only $29 \%$ and $25 \%$ used condoms during their first and last sexual intercourse, respectively. The low and inconsistent use of condoms during sexual intercourse, having sex with multiple sexual partners is a cause for concern, especially considering the fact that there is no cure for HIV and AIDS infection, and this warrants the intensification of HIV and AIDS prevention methods and special focus should be placed on effective use of condoms.

Our study also found associations between knowledge and age, social status, and sources of information $(\mathrm{p}=<0.05)$. Attitudes were also associated with gender, age, race, social status and sources of information $(\mathrm{p}=<0.05)$. Practices were associated with age, race, social class and sources of information $(\mathrm{p}=<0.05)$. There were no associations between knowledge and gender, race and type of settlement. Lastly, we found no association between attitudes and the type of settlement $(\mathrm{p}=>0.05)$, and practices were not associated with gender and type of settlement $(\mathrm{p}=>0.05)$.

These findings were in contrast to those of a study that was conducted $[15,38]$ in Ghana, in which no association was found between the socio-demographic factors and knowledge, attitudes and practices of the respondents.

\section{LIMITATIONS AND STRENGTHS OF THE STUDY}

This study was a descriptive study in nature, therefore, there were limitations on making inferences about the meaning of the results. The study was restricted to only two high schools in two districts, in a limited area, namely, Nelson Mandela Bay Municipality in the Eastern Cape Province of South Africa. This limits the generalisation of findings to the larger provincial, national and international contexts. The research instrument was self-administered, therefore, social desirability might have occurred. It is, however, assumed that the anonymity of the respondents encouraged them to give honest responses. Despite all the above-mentioned limitations, the researcher believes that this study can be utilised as baseline data for further research initiatives within the municipality and the field. It can also be used as a valuable source of information to policymakers, researchers and health promotion practitioners and educators to inform policy direction and future HIV and AIDS health education and sexual education interventions at schools and in the municipality. The results can also be used to inform the design and development of teacher or learner support material. Life orientation teachers can also use the results of this study to establish areas where they need to concentrate on.

\section{RECOMMENDATION}

It is recommended that HIV and AIDS health education campaigns and community outreach interventions in the Nelson Mandela Municipality in the Eastern Cape Province of South Africa be intensified, and special focus be given to youth between 14-21 years. Such interventions should pay special focus on issues regarding transmission, prevention, and management of HIV and AIDS. Sexual education at schools should be intensified in order to rectify the observed misconceptions, negative attitudes and discriminatory practices towards people living with HIV and AIDS and risky and unsafe practices. In the future, a similar study should be done to compare HIV and AIDS knowledge, attitudes and practices between in-school and out-of-school youth. Further research 
can also concentrate on ways of accelerating health education interventions in the Nelson Mandela Municipality in order to close the observed gap in knowledge, attitudes and prevention practices, so that the Sustainable Development Goals 3.3 of eliminating or ending HIV and AIDS as a public health threat by 2030 become an achievable reality.

\section{CONCLUSION}

The study assessed knowledge of HIV and AIDS knowledge, attitudes, and practices among high school learners in the Eastern Cape of South Africa. Learners indicated that their main source of HIV and AIDS was teachers and healthcare workers. It is, therefore, evident that schools are well placed to equip learners with appropriate HIV and AIDS information. In this study, HIV and AIDS knowledge was high, even though some misconceptions and gaps were observed in some areas.

High HIV and AIDS knowledge did not translate to safe sexual practices, such as consistent use of condoms and having one sexual partner. Some of the high school learners believed that HIV and AIDS were transmitted through witchcraft, mosquito bites and handshakes, and that highlighted the need for the intensification of sexual education. More than half of the respondents had negative attitudes towards people living with HIV and AIDS and risky sexual practices regarding HIV and AIDS. Some of the socio-demographic characteristics of the respondents were associated with knowledge attitudes and practices regarding HIV and AIDS, whereas others were not. There was an association between knowledge and age, social status and sources of information. An association between attitudes and gender, age, race, social status and sources of information was found. Practices were associated with age, race, social class and sources of information. No associations were observed between knowledge and gender, race and type of settlement. There was no association between attitudes and the type of settlement, and practices were not associated with gender and type of settlement.

\section{ETHICS APPROVAL AND CONSENT TO PARTI- CIPATE}

The approval for the study protocol, assent and consent procedures was granted by the University of Stellenbosch's Research Ethics Committee (clearance certificate 259/18).

\section{HUMAN AND ANIMAL RIGHTS}

No animals were used in this research. All human research procedures were followed in accordance with the ethical standards of the committee responsible for human experimentation (institutional and national), and with the Helsinki Declaration of 1975, as revised in 2013.

\section{CONSENT FOR PUBLICATION}

Informed consent was obtained from all respondents. All participants and their guardians gave their consent to participate in this study.

\section{STANDARDS OF REPORTING}

STROBE guidelines and methodologies have been followed in this study.

\section{AVAILABILITY OF DATA AND MATERIALS}

The data supporting the findings of the article is available from corresponding author [T.F] upon reasonable request.

\section{FUNDING}

None.

\section{CONFLICT OF INTEREST}

The authors declare no conflict of interest, financial or otherwise.

\section{ACKNOWLEDGEMENTS}

The author would like to thank all the participants and the Provincial Department of Education for granting permission to access their schools and conduct this study.

\section{REFERENCES}

[1] Fana TE. HIV and AIDS knowledge among residents of informal settlements in Port Elizabeth South Africa. Int J HIV/AIDS Preven Edu Behav Sci 2018; 4(2): 57-65.

[http://dx.doi.org/1011648/ijhpebs.20180402.15]

[2] Mwamwenda TS. HIV/AIDS knowledge of high school adolescents in Kenya. J AIDS HIV Res 2013; 5(12): 472-8. [http://dx.doi.org/0.5897/JAHR2013.0278]

[3] Tadese A, Menasbo B. Knowledge, attitude and practices regarding HIV and AIDS among secondary school students in the Mekelle City, Ethiopia. African J AIDS HIV Res 2013; 1(1): 1-7.

[4] UNAIDS 2019 Global HIV and AIDS statistics - 2019 fact sheet 2019 Available from: https://www.unaids.org/en/resources/fact-sheet

[5] Human sciences research council South african national hiv prevalence, incidence, behaviour and communication survey. Cape Town, South Africa: HSRC Press 2018.

[6] Shitan M, Nazrul IM. HIV/AIDS epidemic in Malaysia: trend analysis from 1986 - 2011. South Afr J Demo 2015; 16(1): 37-56.

[7] Masoda M, Govender I. Knowledge and attitudes about and practices of condom use for reducing HIV infection among Goma University students in the Democratic Republic of Congo. South Afr J Epidemiol Infect 2013; 28(1): 61-8.

[http://dx.doi.org/10.1080/10158782.2013.11441521]

[8] Olubayo-Fatiregum MA. Knowledge of HIV/AIDS and risk behaviour among students of College of Education in Edo State, Nigeria. J Educ Soc Res 2014; 4(6): 251-8.

[9] Nubed CK, Akoachere JTK. Knowledge, attitudes and practices regarding HIV/AIDS among senior secondary school students in Fako Division, South West Region, Cameroon. BMC Public Health 2016; 16(1): 847 .

[http://dx.doi.org/10.1186/s12889-016-3516-9] [PMID: 27549185]

[10] Doku D. Substance use and risky sexual behaviours among sexually experienced Ghanaian youth. BMC Public Health 2012; 12(1): 571 [http://dx.doi.org/10.1186/1471-2458-12-571] [PMID: 22839700]

[11] Huda MN, Amanullah DA. HIV/AIDS related knowledge among secondary school students in Bangladesh: A cross sectional study. Adv Infect Dis 2013; 3: 274-80.

[http://dx.doi.org/10.4236/aid.2013.34042]

[12] Somba MJ, Mbonile M, Obure J, Mahande MJ. Sexual behaviour, contraceptive knowledge and use among female undergraduates' students of Muhimbili and Dar es Salaam Universities, Tanzania: a cross-sectional study. BMC Womens Health 2014; 14(1): 94. [http://dx.doi.org/10.1186/1472-6874-14-94] [PMID: 25099502]

[13] Azeez A, Yongsong Q, James N. Risky sexual behaviour and knowledge of HIV/AIDS among high school students in Eastern Cape South Africa. J Hum Ecol 2016; 53(3): 194-204

[http://dx.doi.org/10.1080/09709274.2016.11906972]

[14] Chen PF. HIV/AIDS prevention among young people in East and South-East Asia in the context of reproductive and sexual health. Asia Pacific Population 2008; 23(1): 7. [http://dx.doi.org/10.18356/2f9cf12d-en] 
[15] Dzah SM, Tarkang EE, Lutala PM. Knowledge, attitudes and practices regarding HIV/AIDS among senior high school students in SekondiTakoradi metropolis, Ghana. Afr J Prim Health Care Fam Med 2019; 11(1): e1-e11.

[http://dx.doi.org/10.4102/phcfm.v11i1.1875] [PMID: 31170791]

[16] Fana T, Mayekiso T, Gwandure C. Assessment of community member's knowledge of drug resistant tuberculosis and HIV and AIDS in the Eastern Cape Province, South Africa. Afr Insight 2013; 43(2): 59-73.

[17] Gudi SK. Assessment of knowledge, attitudes and perceptions of HIV/AIDS among secondary students in Guntur District of South India: A cross sectional survey. Int J Sci Res 2018; 4(4): 87-92. [http://dx.doi.org/10.18203/issn.2454-2156.IntJSciRep20181392]

[18] Kumar P, Pore P, Patril U. HIV/AIDS related KAP among high-school students of Municipal Corporation School in Pune. An interventional study. Natl J Community Med 2012; 3(1): 74-9.

[19] Azeez A, Yongsong Q, Akinwumi O, James N. Knowledge, attitudes and practices of HIV/AIDS among high school students in Eastern Cape, South Africa. J Hum Ecol 2016; 54(2): 78-86.

[http://dx.doi.org/10.1080/09709274.2016.11906989]

[20] Christane NA, Zamba Mr, Masika J, Zhang Y, Zhang L. HIV/AIDS prevalence, knowledge, attitudes and related behaviour among young people in Libreville, Gabon. IOSR J HumanitSoc Sci 2014; 19(1): 59-65.

[http://dx.doi.org/10.9790/0837-19125965]

[21] Yaya S, Bishwajit G, Danhoundo G, Seydou I. Extent of knowledge about HIV and Its determinants among Men in Bangladesh. Front Public Health 2016; 4(246): 246

[http://dx.doi.org/10.3389/fpubh.2016.00246] [PMID: 27857939]

[22] Gwandure C, Mayekiso T. Fear and guilt in HIV and AIDS prevention. Afr Insight 2011; 41: 35-47.

[http://dx.doi.org/10.4314/ai.v41i1.68370]

[23] Zungu NP, Simbayi LC, Mabaso M, et al. HIV risk perception and behavior among medically and traditionally circumcised males in South Africa. BMC Public Health 2016; 16: 357.

[http://dx.doi.org/10.1186/s12889-016-3024-y] [PMID: 27112917]

[24] Leclerc-Madlala S. Age-disparate and intergenerational sex in southern Africa: The dynamics of hypervulnerability. AIDS 2008; 22(4)(Suppl. 4): S17-25.

[http://dx.doi.org/10.1097/01.aids.0000341774.86500.53] [PMID: 19033752]

[25] Upreti D, Regmi P, Pant P, Simkhada P. Young people's knowledge, attitude, and behaviour on STI/HIV/AIDS in the context of Nepal: A systematic review. Kathmandu Univ Med J 2009; 7(28): 383-91. [http://dx.doi.org/10.3126/kumj.v7i4.2759] [PMID: 20502079]

[26] Pettifor AE, Rees HV, Kleinschmidt I, et al. Young people's sexual health in South Africa: HIV prevalence and sexual behaviors from a nationally representative household survey. AIDS 2005; 19(14): 1525-34. [http://dx.doi.org/10.1097/01.aids.0000183129.16830.06] [PMID: 16135907]

[27] CDC- Division of HIV/AIDS prevention HIV among women. Atlanta GA: Centre for Disease Control and Prevention 2013.

[28] Appiah-Agyekum NN, Suapim RH. Knowledge and awareness of HIV/AIDS among high school girls in Ghana. HIV AIDS (Auckl) 2013; 5: 137-44.

[http://dx.doi.org/10.2147/HIV.S44735] [PMID: 23847431]

[29] Agyemang S, Buor D, Tagoe-Darko E. The extent of knowledge about HIV/AIDS among young people in the Ejuka-Sekyedumase District in Ghana. J AIDS HIV Res 2012; 4(11): 241-7.

[http://dx.doi.org/10.5897/JAHR12.023]

[30] Selesho JM, Modishe AM. Strategies in dealing with HIV/AIDS in our schools: Changing the lenses. J Hum Ecol 2012; 38(3): 181-9.

[http://dx.doi.org/10.1080/09709274.2012.11906487]

[31] Dzugudzha NT, Mokgatle MM, Madiba S. Knowledge of HIV/AIDS and perceptions about HIV-positive people among primary school learnrs in Soshanguve, Pretoria, South Africa, African Journal for Physical, Health Education. Recreation and Dance 2015; 2(1): 112-22.

[32] Thanavahn B, Rashid HO, Kasuya H, Sakamoto J. Knowledge, attitudes and practices regarding HIV/AIDS among male high school learners in Lao Peoples Democratic Republic. J Int AIDS Soc 2013; 16: 173-87.

[33] Haddison EC, Nguefack-Tsagué G, Noubom M, Mbatcham W, Ndumbe PM, Mbopi-Kéou FX. Voluntary counseling and testing for HIV among high school students in the Tiko health district, Cameroon. Pan Afr Med J 2012; 13: 18. [PMID: 23308323]

[34] Okwari EE, Nwadioha SI, Akogwa GE, Agbo JE, Ekoja JA, Adole PE. Awareness of HIV/AIDS among primary school pupils in north central region of Nigeria. Asian Pac J Trop Dis 2012; 2(1): 60-7.

[http://dx.doi.org/10.1016/S2222-1808(12)60014-0]

[35] Tenkorang EY. Myths and misconceptions about HIV transmission in Ghana: what are the drivers? Cult Health Sex 2013; 15(3): 296-310.

[http://dx.doi.org/10.1080/13691058.2012.752107] [PMID: 23240740]

[36] Ishikawa N, Pridmore P, Carr-Hill R, Chaimuangdee K. The attitudes of primary schoolchildren in Northern Thailand towards their peers who are affected by HIV and AIDS. AIDS Care 2011; 23(2): 237-44. [http://dx.doi.org/10.1080/09540121.2010.507737] [PMID: 21259137]

[37] Adeleke IT, Azeez BA, Aliyu D, Ogundiran LM, Salami A, Adeoye WA. HIV/AIDS awareness among secondary schools adolescents in South Western Nigeria: A correlate to strengthen advocacy and strategic sexuality education programs. AJHR 2015; 3(1): 61-7. [http://dx.doi.org/10.11648/j.ajhr.s.2015030101.19]

[38] Steenkamp L, Venter D, Walsh C, Dana P. Socio-economic and demographic factors related to HIV status in urban informal settlements in the Eastern Cape, South Africa. Afr J AIDS Res 2014; 13(3): 271-9.

[http://dx.doi.org/10.2989/16085906.2014.952651] [PMID: 25388981]

(C) 2021 Thanduxolo Fana

This is an open access article distributed under the terms of the Creative Commons Attribution 4.0 International Public License (CC-BY 4.0), a copy of which is available at: https://creativecommons.org/licenses/by/4.0/legalcode. This license permits unrestricted use, distribution, and reproduction in any medium, provided the original author and source are credited. 